\title{
Where are the low-calorie sweeteners? An analysis of the presence and types of low-calorie sweeteners in packaged foods sold in Brazil from food labelling
}

\author{
Luiza dos Santos Figueiredo ${ }^{1,2}$, Tailane Scapin ${ }^{1,3}$, Ana Carolina Fernandes ${ }^{1,3}$ and \\ Rossana Pacheco da Costa Proença ${ }^{1,3, *}$ \\ 'Nutrition in Foodservice Research Centre (Núcleo de Pesquisa de Nutrição em Produção de Refeições - NUPPRE), \\ Federal University of Santa Catarina (Universidade Federal de Santa Catarina - UFSC), Health Sciences Centre, \\ Reitor João David Ferreira Lima Campus, 88040-900 Florianópolis, SC, Brazil: ${ }^{2}$ Departament of Nutrition \\ (Departamento de Nutrição), Federal University of Santa Catarina (Universidade Federal de Santa Catarina - \\ UFSC), Health Sciences Centre, Florianópolis, SC, Brazil: ${ }^{3}$ Nutrition Postgraduate Programme (Programa de Pós- \\ graduação em Nutrição - PPGN), Federal University of Santa Catarina (Universidade Federal de Santa Catarina - \\ UFSC), Health Sciences Centre, Florianópolis, SC, Brazil
}

Submitted 10 February 2017: Final revision received 8 August 2017: Accepted 22 August 2017: First published online 26 October 2017

\begin{abstract}
Objective: Studies have shown that consumption of low-calorie sweeteners (LCS) may be associated with harmful health effects. The current study investigated the presence and types of LCS added to packaged foods.

Design: Cross-sectional study analysing the presence and types of LCS in the ingredients lists of packaged foods sold at a major Brazilian supermarket. To identify types of LCS allowed for use in foods in Brazil, current legislation was consulted. Data were organised and analysed through descriptive statistics, presenting simple and relative frequencies of LCS presence categorised by food group.

Setting: Supermarket in Florianópolis, southern Brazil.

Subjects: Packaged food products ( $n$ 4539) from eight food groups.

Results: One or more LCS were found in 602 (13.3\%) of the packaged foods analysed. There were 1329 citations of LCS among these foods, with a mean of $2 \cdot 2$ sweeteners per food. Groups with the highest frequency of foods containing LCS were: products with energy derived from carbohydrates and fats (25.0\%); milk and dairy products $(11.7 \%)$; bakery products, cereals, legumes, roots and tubers $(11.2 \%)$; and fruits, juices, nectars and fruit drinks (8.3\%).

Conclusions: There was high prevalence of packaged foods with LCS, especially in food groups that form the basis of the Brazilian diet. The study was the first to extensively analyse the presence and types of LCS in packaged foods available for sale in a Brazilian supermarket and can be useful to monitor the use of LCS in these foods, as well as to support future changes in legislation to label sugars.
\end{abstract}

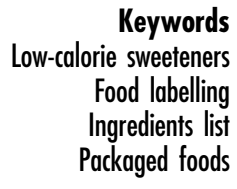

Low-calorie sweeteners (LCS) are defined as partial or total substitutes for sugars that give foods a sweeter flavour ${ }^{(1)}$. The consumption of LCS appears to have increased in recent years among people of all age groups. It is estimated that $28 \%$ of the world's population consumes LCS. This is partly due to the growth in the market of packaged foods referred to as 'diet' foods and beverages ${ }^{(2,3)}$.

The purpose of using LCS in food and drink processing is mainly to provide a sweeter flavour without increasing the energy content ${ }^{(4)}$. However, the relationship between the ingestion of LCS and energy consumption is still unclear $^{(5,6)}$. Studies have shown that the sweeter a product is (regardless of its energy content), the greater its consumption will be ${ }^{(7)}$. Due to their sweet flavour, foods containing LCS can affect the brain's satiety system and lead to compensation for the low energy consumption, thereby increasing subsequent energy intake ${ }^{(5,8)}$.

There is scientific evidence pointing to a significant association between the replacement of sugars with LCS in glycaemic responses and weight loss in adults ${ }^{(9,10)}$. However, studies have also shown that the frequent consumption of LCS seems to be associated with a higher 
risk of excessive weight gain ${ }^{(8,11,12)}$, type 2 diabetes $^{(8,13)}$, metabolic syndrome and $\mathrm{CVD}^{(8,14)}$. One of the physiological mechanisms of LCS is the possible induction of glucose intolerance by interacting with sweet taste receptors in the digestive system that play a role in glucose absorption and stimulate insulin secretion ${ }^{(15)}$. It is still necessary to clarify certain issues regarding the properties and effects of LCS on the human organism as well as how consumers choose to use them ${ }^{(5)}$.

Some evidence has pointed to harmful health effects related to the consumption of $\operatorname{LCS}^{(8,12,13)}$. Thus, some official organisations recommend not using LCS as a sugar substitute $^{(16)}$. Nevertheless, regardless of official recommendations, consumers may want to avoid or control their consumption of such sweeteners as a personal choice.

One source of information available to consumers about the presence of LCS in packaged foods is food labels, and specifically ingredients lists, which enable them to identify the presence, but not the amount, of such sweeteners ${ }^{(1,17)}$. Reporting the ingredients and additives used in these foods is mandatory in many countries, including Brazil ${ }^{(18)}$.

We found only two studies worldwide that identified the presence of LCS in packaged foods ${ }^{(19,20)}$, both of which were conducted in North America. A study conducted in the USA observed that $7 \%$ of foods contained LCS. However, it should be noted that the study's data are from 2005-2009 ${ }^{(19)}$. Another study conducted in Canada (based on a database that was updated in 2013) found that $3.7 \%$ of foods contained LCS ${ }^{(20)}$. In Brazil, a search of indexed journals found no studies that identified the presence of LCS in packaged foods.

Therefore, the present study aimed to investigate the presence and types of LCS added to all packaged foods available for sale at a major Brazilian supermarket.

\section{Methods}

\section{Study design}

The current study is a cross-sectional one in which all retailed packaged food products available in a large supermarket in Brazil were investigated. The supermarket chosen belongs to one of the three largest Brazilian chains, according to the Brazilian Supermarket Association, with twenty-seven stores throughout the country ${ }^{(21)}$. Among these three chains, we chose the only one that had stores in the state where the research was carried out. Therefore, most of the products sold in this store are well-known food and drink brands and represent those sold in other large supermarket chain stores throughout Brazil. The same study design and collection methods have been used in previous studies ${ }^{(22-24)}$.

A census was carried out in which all aisles in the supermarket were mapped and each collector was responsible for collecting information on every food product present in the aisles assigned to him/her. All packaged food products available in the supermarket that met the criteria established by Brazilian and Mercosur food labelling regulations (no. 360/ 2003) were included in the audit ${ }^{(17)}$. Products not included in the study were those covered by different regulations (i.e. food for babies and toddlers) or those that did not require nutrition labelling (i.e. bakery products produced, packaged and labelled in-store; and meat and cheese products cut, packaged and labelled in-store) ${ }^{(25)}$. The supermarket manager gave written consent for the research.

\section{Data collection}

Data were gathered over a three-month period (October to December 2013) in the city of Florianópolis in the state of Santa Catarina in southern Brazil. Information on identification (product name and type), nutritional values (energy, carbohydrates, protein, total fat, saturated fat, trans fat, fibre and sodium per serving) and serving sizes was obtained in the store from the labels of all available products. These data were then entered into electronic data collection forms developed by Kliemann et al. ${ }^{(26)}$. The electronic version was created using Epi Collect Plus software and installed on tablet computers. Information on the packages of the same products of different sizes was recorded separately, as their serving sizes and nutritional values sometimes differed. All food labels were photographed in the store to collect the ingredients lists. Inter-variable agreement between the data collected with the electronic questionnaire and the data collected with the photographs was checked for $5 \%$ of the food products analysed, to control for quality. According to the $\kappa$ test, there was a high degree of inter-variable agreement $(>99 \% ; P<0.05)$.

All data collectors ( $n$ 12) were trained and participated in a field test of the instrument at a different supermarket one month before the data collection. They were asked to fill out the electronic forms with information from fifteen food products from different food groups, individually and without help, and the information was double-checked by the main researcher. The data were subsequently examined, difficulties and inconsistencies were identified, and extra training was then provided.

\section{Data management}

The collected data were transferred directly from the tablet computers to an online database at the end of each collection day. The database was exported to a Microsoft ${ }^{\circledR}$ Excel 2010 spreadsheet. Each food product was coded with a number and each image in the database was later renamed according to the corresponding food product number.

\section{Identification of low-calorie sweeteners in packaged foods}

The National Sanitary Surveillance Agency (ANVISA) was consulted to identify which LCS are permitted for use in Brazil. Thus, fifteen groups of LCS with eighteen distinct names were identified, according to Brazilian food labelling regulations: (i) sorbitol, sorbitol syrup, D-sorbitol; (ii) mannitol; (iii) acesulfame potassium; (iv) aspartame; 
(v) cyclamic acid and its calcium, potassium and sodium salts; (vi) isomalt (isomaltitol); (vii) saccharin and its calcium, potassium and sodium salts; (viii) sucralose; (ix) thaumatin; (x) steviol glycosides; (xi) neotame; (xii) maltitol, maltitol syrup; (xiii) lactitol; (xiv) xylitol; and (xv) erythritol ${ }^{(1)}$. Variations in the names of LCS in the ingredient lists were also considered.

Based on these photographic records, all ingredients and food additives found on the label of each product were transcribed into a Microsoft Excel 2010 spreadsheet. For quality control purposes, three researchers checked the transcribed data. Terms identified in the regulations on LCS were used to identify the presence and types of LCS in the foods, according to the transcribed ingredients lists.

The packaged foods were classified into eight food groups based on their similarities in terms of nutritional composition, as defined by Brazilian and Mercosur resolutions ${ }^{(25)}$. The groups were as follows: (i) baking goods, breads, cereals, legumes, roots, tubers and related products; (ii) canned vegetables; (iii) fruits, juices, syrups and drink mixes; (iv) milk and dairy products; (v) meat and eggs; (vi) oils, fats and nuts; (vii) products in which carbohydrates and fats are the main energy sources; and (viii) gravies, sauces, ready-made seasonings, broths, soups and ready-to-eat dishes. Cluster analysis was used to identify the frequency of appearance of the LCS by group ${ }^{(27)}$. In order to identify the types of foods containing low-calorie sweeteners within the groups with the highest prevalence, these foods were classified into subgroups, as suggested by Brazilian regulation ${ }^{(25)}$.

The data obtained were organised and analysed using descriptive statistics by simple and relative frequencies of the presence of LCS in the foods according to food group, to obtain an overview of their use in packaged foods sold in Brazil.

\section{Results}

We analysed the ingredients lists of 4539 packaged foods available for sale during the data collection period, of which
$602(13.3 \%)$ contained some type of LCS. Table 1 shows the number and proportion of foods with LCS by food group.

The group with the greatest predominance of foods containing LCS was the group of products with energy derived from carbohydrates or fats, in which $25.0 \%$ of the foods had at least one type of LCS in their composition. The milk and dairy products; bakery products, cereals, legumes, roots and tubers; and fruits, juices, nectars and fruit drinks groups also had a considerable proportion of foods that contained LCS: $11 \cdot 7,11.2$ and $8.3 \%$, respectively.

The subgroups within the food groups with the highest proportion of LCS are presented in Table 2.

In the bakery products, cereals, legumes, roots and tubers group, the following subgroups had the highest proportions of foods containing LCS: cakes without filling; powders for flan and dessert preparation; and cereal bars. In the fruits, juices, nectars and fruit drinks group, the following subgroups had the highest prevalence of LCS: juices, nectars and fruit drinks; and canned fruit. In the milk and dairy products group, the dairy dessert preparation powders and dairy drinks subgroups had the highest prevalence of foods containing LCS.

In the group of products with energy derived from carbohydrates or fats, the following subgroups had the highest prevalence of foods containing LCS: drink preparation powders; cakes and similar foods with filling and/ or frosting; gelatine powders; and non-alcoholic drinks. All the foods in the powdered drinks subgroup had LCS. Thus, there were no powdered drinks without LCS available for sale. In the other subgroups, there were few options that did not contain LCS, such as in cakes without filling or frosting, dairy dessert mixes, cakes with filling and frosting, chewing gum and soft drinks. Furthermore, some subgroups containing LCS (such as bread and salted crackers) consist of foods that have a salty taste, which shows that the use of LCS is not limited to sweet foods.

There were 1329 citations of LCS among the 602 foods with these additives, with a mean of $2 \cdot 2$ LCS citations per food. Table 3 shows the frequency of citation of the LCS in the database.

Table 1 Characterisation of the packaged foods database and the presence of low-calorie sweeteners (LCS), according to food group, in 4539 packaged food products available in a large supermarket in Florianópolis, Santa Catarina, Brazil, October-December 2013

\begin{tabular}{lccc}
\hline Food group & $\begin{array}{c}\text { No. of foods } \\
\text { in group }\end{array}$ & $\begin{array}{c}\text { No. of foods } \\
\text { containing LCS }\end{array}$ & $\begin{array}{r}\text { Prevalence of foods } \\
\text { containing LCS (\%) }\end{array}$ \\
\hline $\begin{array}{l}\text { Bakery goods, bread, cereals, legumes, roots, } \\
\quad \text { tubers and related products }\end{array}$ & 941 & 105 & 11.2 \\
Canned vegetables & 221 & 1 & 0.5 \\
Fruits, juices, syrups and drink mixes & 229 & 19 & 8.3 \\
Milk and dairy products & 359 & 42 & 11.7 \\
Meats and eggs & 484 & 2 & 0.4 \\
Oils, fats and nuts & 280 & 2 & 0.7 \\
Products in which carbohydrates and fats are the & 1717 & 429 & $25 \cdot 0$ \\
$\quad$ main energy sources & 308 & 2 & 0.6 \\
$\quad$ Gravies, sauces, ready-made seasonings, broths & & & 13.3 \\
$\quad$ and ready-to-eat dishes & 4539 & 602 & 2 \\
TOTAL & &
\end{tabular}


Table 2 Classification of foods containing low-calorie sweeteners (LCS), according to food group and subgroup of RDC no. 359/2003(25), in 4539 packaged food products available in a large supermarket in Florianópolis, Santa Catarina, Brazil, October-December 2013

\begin{tabular}{|c|c|c|c|c|}
\hline Food group & Subgroup containing LCS & $\begin{array}{l}\text { No. of foods } \\
\text { in subgroup }\end{array}$ & $\begin{array}{l}\text { No. of foods } \\
\text { containing LCS }\end{array}$ & $\begin{array}{l}\text { Prevalence of foods } \\
\text { containing LCS (\%) }\end{array}$ \\
\hline \multirow{8}{*}{$\begin{array}{l}\text { Bakery goods, bread, cereals, legumes, } \\
\text { roots, tubers and related products }\end{array}$} & Cakes without filling or frosting & 28 & 20 & 71.4 \\
\hline & Flan and dessert mixes & 24 & 14 & $58 \cdot 3$ \\
\hline & Granola bars & 79 & 22 & $27 \cdot 8$ \\
\hline & Breakfast cereals & 76 & 14 & $18 \cdot 4$ \\
\hline & Salted crackers & 114 & 20 & 17.5 \\
\hline & Bread & 62 & 9 & 14.5 \\
\hline & Cake mix & 67 & 5 & 7.5 \\
\hline & Cereal flour and tuber flour & 70 & 1 & 1.4 \\
\hline Canned vegetables & Pickled vegetables & 65 & 1 & 1.5 \\
\hline \multirow[t]{2}{*}{ Fruits, juices, syrups and drink mixes } & Canned fruit & 20 & 2 & $10 \cdot 0$ \\
\hline & Juice, nectars and fruit drinks & 185 & 17 & $9 \cdot 2$ \\
\hline \multirow[t]{2}{*}{ Milk and dairy products } & Dairy dessert mixes & 33 & 21 & 63.6 \\
\hline & $\begin{array}{l}\text { Dairy drinks, fermented milk and } \\
\text { yoghurt }\end{array}$ & 267 & 21 & 7.9 \\
\hline Meats and eggs & Kani-kama & 3 & 2 & $66 \cdot 6$ \\
\hline Oils, fats and nuts & Chantilly & 6 & 2 & 33.3 \\
\hline \multirow{18}{*}{$\begin{array}{l}\text { Products in which carbohydrates and fats } \\
\text { are the main energy sources }\end{array}$} & Powdered drinks & 72 & 72 & $100 \cdot 0$ \\
\hline & Cakes with filling and frosting & 56 & 49 & 87.5 \\
\hline & Jelly & 76 & 65 & 85.5 \\
\hline & Chewing gum & 15 & 9 & $60 \cdot 0$ \\
\hline & Soft drinks & 266 & 133 & $50 \cdot 0$ \\
\hline & Panettone & 51 & 10 & $19 \cdot 6$ \\
\hline & Coffee mix & 29 & 5 & $17 \cdot 2$ \\
\hline & Chocolate powders & 24 & 4 & $16 \cdot \overline{6}$ \\
\hline & Peanut candy & 26 & 4 & $15 \cdot 4$ \\
\hline & Candies & 125 & 15 & $12 \cdot 0$ \\
\hline & Chocolate, chocolate candies & 249 & 28 & $11 \cdot 2$ \\
\hline & Jam & 158 & 17 & $10 \cdot 8$ \\
\hline & $\begin{array}{l}\text { Ice cream in individual portions } \\
\text { and popsicles }\end{array}$ & 120 & 10 & 8.3 \\
\hline & Bakery goods & 12 & 1 & $8 \cdot 3$ \\
\hline & Chocolate topping & 21 & 1 & 4.8 \\
\hline & $\begin{array}{l}\text { With glucose, honey, molasses, } \\
\text { syrup, condensed milk }\end{array}$ & 49 & 1 & $2 \cdot 0$ \\
\hline & Cookies & 268 & 5 & 1.8 \\
\hline & Snacks/processed snacks & 160 & 1 & 0.6 \\
\hline $\begin{array}{l}\text { Gravies, sauces, ready-made seasonings, } \\
\text { broths and ready-to-eat dishes }\end{array}$ & Popcorn & 260 & 2 & 0.8 \\
\hline
\end{tabular}

The three most commonly cited LCS were acesulfame potassium, sucralose and aspartame. Some LCS were not found in the packaged foods investigated, as was the case for D-sorbitol, erythritol and thaumatin. It is assumed that either the use of these additives is very uncommon in packaged foods and thus they were not identified in the foods available for sale during the period of investigation, or that there may have been variations in their names that could not be identified and are not cited by current food labelling regulations.

\section{Discussion}

To our knowledge, the present study is the first to analyse the presence and types of LCS in packaged foods available for sale outside North America.

The proportion of packaged foods containing LCS found in the present study (13.3\%) was approximately twice the proportion found in a US study (7\%) that analysed a database with food data from 2005 to $2009^{(19)}$ and
$3 \cdot 6$ times greater than the proportion found in a Canadian study $(3.7 \%)$ that analysed a food database that was updated in the same year the data for the present study were collected ${ }^{(20)}$.

As expected, the group with the greatest predominance of foods containing LCS was the group of products with energy derived from carbohydrates or fats. This is due to the fact that the foods in this group characteristically have sweet flavours, which LCS are meant to provide ${ }^{(1)}$. It is worth noting that most of the foods in the database belong to this group. Thus, they are the main packaged foods available to Brazilian consumers.

Bakery products, cereals, legumes, roots and tubers also accounted for more than $10 \%$ of the foods containing LCS. Many foods in this category, such rice and beans, form the basis of the Brazilian diet. However, the intake of rice and beans has been decreasing while the intake of processed foods that have LCS in their composition (such as bread, cakes and granola bars) has been increasing ${ }^{(28)}$. 
Table 3 Citation frequency (in descending order) of low-calorie sweeteners (LCS) in ingredients lists on the labels of 602 LCScontaining packaged foods available in a large supermarket in Florianópolis, Santa Catarina, Brazil, October-December 2013

\begin{tabular}{lcc}
\hline LCS & No. of citations & Citation frequency (\%) \\
\hline Acesulfame potassium & 266 & $20 \cdot 1$ \\
Sucralose & 222 & $16 \cdot 8$ \\
Aspartame & 193 & $14 \cdot 6$ \\
Sorbitol & 166 & $12 \cdot 5$ \\
Cyclamate & 165 & $12 \cdot 5$ \\
Saccharin & 159 & $12 \cdot 0$ \\
Maltitol & 60 & $4 \cdot 5$ \\
Stevia & 48 & $3 \cdot 6$ \\
Isomalt & 17 & $1 \cdot 3$ \\
Mannitol & 10 & $0 \cdot 8$ \\
Lactitol & 6 & $0 \cdot 5$ \\
Sorbitol syrup & 5 & $0 \cdot 4$ \\
Xylitol & 4 & $0 \cdot 3$ \\
Maltitol syrup & 2 & $0 \cdot 2$ \\
Neotame & 1 & $0 \cdot 1$ \\
D-Sorbitol & 0 & $0 \cdot 0$ \\
Erythritol & 0 & $0 \cdot 0$ \\
Thaumatin & 0 & $0 \cdot 0$ \\
TOTAL & 1329 & $100 \cdot 0$ \\
\hline
\end{tabular}

According to the Brazilian Family Budget Survey, the mean consumption of juice and fruit drinks increased between 2002 and 2009 ${ }^{(28)}$. Juices, fruit drinks and canned fruits had a high proportion of foods containing LCS, and many countries and health experts do not consider them as a source of fruits ${ }^{(16,29)}$. Thus, it is important to recommend the consumption of whole fruits, as the ingestion of processed fruit products can also lead to LCS intake, as shown by the results reported here.

In the milk and dairy products group, LCS were found in foods such as dairy dessert preparation powders, dairy drinks and yoghurts. The consumption of dairy products is recommended by dietary guidelines around the world, including the US Dietary Guidelines for Americans ${ }^{(16)}$ and England's Eatwell Guide ${ }^{(30)}$. However, these recommendations do not consider how such foods are processed. The Dietary Guidelines for the Brazilian Population ${ }^{(31)}$ consider the degree of food processing and encourage the consumption of natural and minimally processed foods, as well as restricting the consumption of processed and ultraprocessed foods (packaged foods).

Regarding the types of LCS present in the investigated foods, the three most commonly cited were acesulfame potassium, sucralose and aspartame. The same result was found in a study conducted in the USA that evaluated LCS in sweetened diet drinks ${ }^{(19)}$, demonstrating a convergence in the types of LCS used in the two countries.

The present study's results indicate that there are many names for the LCS allowed under Brazilian law ${ }^{(1)}$, which can complicate their identification by consumers, as the variety and complexity of the names can be confusing. Thus, this complicates adherence to recommendations of the WHO's Global Strategy for Healthy Eating, Physical Activity and Health, which cite food labelling as an important instrument to provide information on food products in order to equip consumers with the tools they need to make informed food choices ${ }^{(32)}$. Furthermore, studies $^{(33,34)}$ have shown that consumers often have trouble reading food labels and that one of the reasons for this is the use of scientific terms that are difficult to understand. Some measures are being taken to solve this issue. For example, Canada has required that the presence of LCS be displayed on the main panels of food labels ${ }^{(35)}$.

The present study has some limitations. For example, we point out the difficulty of classifying certain packaged foods that are not covered by Regulation no. 359/2003, such as hydroponic and lyophilised vegetables, which were not common in Brazil when the regulation was adopted $^{(25)}$. In addition, the fact that the data were collected from a single supermarket needs to be considered. Nevertheless, care was taken in selecting the supermarket so that our database would include products that can be found in any other part of the country (i.e. brands sold nationwide). Moreover, we believe that our study is the fourth survey in Brazil to investigate aspects of the labels of all food products sold in a single supermarket (the other three studies were also conducted in a single large supermarket $\left.^{(22-24,26,36-42)}\right)$.

\section{Conclusions}

The present study was the first to extensively analyse the presence and types of LCS in packaged foods available for sale in a Brazilian supermarket. Thirteen per cent of the packaged foods analysed in this Brazilian survey contained LCS. Thus, elevated consumption of packaged foods can lead the population to consume LCS, even if there is no specific need for them.

Due a lack of consensus about the health effects of LCS, it is important to start monitoring the prevalence of foods containing LCS. This can be useful to help Brazilian consumers understand types of LCS used in packaged foods, as well as to support changes to food label regulations.

To reduce LCS consumption, it is important to avoid packaged foods, especially sweetened beverages, gelatine powders, cakes and similar products. The identification of LCS in food groups and subgroups can also assist nutritionists in counselling their patients about the types of foods that contain such additives.

Consumers can identify the LCS present in a food product by consulting its ingredients list. However, consumers may have trouble with this identification, as a wide variety of names is used to designate these additives. The disclosure of these names by organisations such as professional councils and associations in the health field could be a strategy to assist consumers in identifying which compounds in packaged foods are LCS.

In the interest of continuity, we suggest conducting studies that evaluate the concomitant presence of LCS and 
added sugars in packaged foods to verify whether or not LCS are being used to reduce the amount of sugars in their composition.

\section{Acknowledgements}

Financial support: The authors thank the Federal Agency for Support and Evaluation of Graduate Education in Brazil (CAPES) for its financial support in the form of scholarships to A.C.F. and T.S. The authors also thank the National Council for Scientific and Technological Development (CNPq) of the Ministry of Science and Technology in Brazil for its financial support in the scholarship to L.S.F. This analysis was conducted as part of a wider study about the comprehension and use of food labelling in Brazil, which was funded by the CNPq of the Ministry of Science and Technology in Brazil and by the Brazilian Health Surveillance Agency (ANVISA) (grant number 440040/ 2014-0), with the aim of filling gaps related to the policies, management and organisation of the Brazilian National Health Surveillance System. CAPES, CNPq and ANVISA had no role in the design, analysis or writing of this article. Conflict of interest: The authors declare that they have no conflicts of interest. Authorship: L.S.F. was responsible for collecting, analysing and interpreting the data, and drafting the manuscript. T.S. was responsible for planning the research, collecting, analysing and interpreting the data, and drafting the manuscript. A.C.F. was responsible for collecting, analysing and interpreting the data, and for revising the manuscript. R.P.C.P. was responsible for research coordination, planning the research and analysis, and supervising and revising the final manuscript. All authors approved the version submitted for publication. Etbics of buman subject participation: Not applicable.

\section{References}

1. Ministry of Health, Brazilian Health Surveillance Agency (2008) Resolution-RDC n. 18, of March 24, 2008 (Provides for the Technical Rules Authorizing the Use of Additives Sweeteners, with their Respective Ceilings). Brasilia, DF: ANVISA.

2. Torloni MR, Nakamura MU, Megale A et al. (2007) The use of sweeteners in pregnancy: an analysis of products available in Brazil. Rev Bras Ginecol Obstet 29, 267-275.

3. Shankar P, Ahuja S \& Sriram K (2013) Non-nutritive sweeteners: review and update. Nutrition 29, 1293-1299.

4. Bellisle F (2015) Intense sweeteners, appetite for the sweet taste, and relationship to weight management. Curr Obes Rep 4, 106-110.

5. Mattes RD \& Popkin BM (2009) Nonnutritive sweetener consumption in humans: effects on appetite and food intake and their putative mechanisms. Am J Clin Nutr 89, 1-14.

6. Anton SD, Martin CK, Han $\mathrm{H}$ et al. (2010) Effects of stevia, aspartame, and sucrose on food intake, satiety, and postprandial glucose and insulin levels. Appetite 55, $37-43$.

7. Holt SHA, Cobiac L, Beaumont-Smith NE et al. (2000) Dietary habits and the perception and liking of sweetness among Australian and Malaysian students: a crosscultural study. Food Qual Prefer 11, 299-312.

8. Swithers SE (2013) Artificial sweeteners produce the counterintuitive effect of inducing metabolic derangements. Trends Endocrinol Metab 24, 431-441.

9. Wiebe N, Padwal R, Field C et al. (2011) A systematic review on the effect of sweeteners on glycemic response and clinically relevant outcomes. BMC Med $\mathbf{9}, 123$.

10. Miller PE \& Perez V (2014) Low-calorie sweeteners and body weight and composition: a meta-analysis of randomized controlled trials and prospective cohort studies. Am J Clin Nutr 100, 765-777.

11. Qurrat-ul-Ain \& Khan SA (2015) Artificial sweeteners: safe or unsafe? J Pak Med Assoc 65, 225-227.

12. Rogers PJ, Hogenkamp PS, de Graaf C et al. (2016) Does low-energy sweetener consumption affect energy intake and body weight? A systematic review, including metaanalyses, of the evidence from human and animal studies. Int J Obes (Lond) 40, 381-394.

13. Greenwood DC, Threapleton DE, Evans CE et al. (2014) Association between sugar-sweetened and artificially sweetened soft drinks and type 2 diabetes: systematic review and dose-response meta-analysis of prospective studies. Br J Nutr 112, 725-734.

14. Johnson RK, Appel LJ, Brands M et al. (2009) Dietary sugars intake and cardiovascular health: a scientific statement from the American Heart Association. Circulation 120, 1011-1020.

15. Pepino MY (2015) Metabolic effects of non-nutritive sweeteners. Physiol Behav 152, 450-455.

16. US Department of Agriculture \& US Department of Health and Human Services (2015) Dietary Guidelines for Americans 2015-2020, 8th ed. Washington, DC: US Government Printing Office; available at http://health.gov/ dietaryguidelines/2015/guidelines

17. Ministry of Health, Brazilian Health Surveillance Agency (2003) Resolution - RDC n. 360, of December 23, 2003 (Approves the Technical Rules for Packaged Food Labelling, and Become it Mandatory). Brasília, DF: ANVISA.

18. Ministry of Health, Brazilian Health Surveillance Agency (2002) Resolution - RDC n. 259, of September 20, 2002 (Approves the Technical Rules for Packaged Food Labelling). Brasília, DF: ANVISA.

19. Ng SW, Slining MM \& Popkin BM (2012) Use of caloric and noncaloric sweeteners in US consumer packaged foods, 2005-2009. J Acad Nutr Diet 112, 1828-1834.e1-6.

20. Bernstein JT, Schermel A, Mills CM et al. (2016) Total and free sugar content of Canadian prepackaged foods and beverages. Nutrients $\mathbf{8}$, E582.

21. Brazilian Supermarket Association (2013) Abras Ranking 2013. Revista SUPERHiPER. Brasília, DF: ABRAS; available at http://www.asbra.com.br/noticia/ranking-abras-2013conheca-as-20-maiores-redes-supermercadistas-do-pais

22. Silveira BM, Gonzalez-Chica DA \& da Costa Proenca RP (2013) Reporting of trans-fat on labels of Brazilian food products. Public Health Nutr 16, 2146-2153.

23. Martins CA, de Sousa AA, Veiros MB et al. (2015) Sodium content and labelling of processed and ultra-processed food products marketed in Brazil. Public Health Nutr 18, 1206-1214.

24. Rodrigues VM, Rayner M, Fernandes AC et al. (2016) Comparison of the nutritional content of products, with and without nutrient claims, targeted at children in Brazil. $\mathrm{Br} \mathrm{J}$ Nutr 115, 2047-2056.

25. Ministry of Health, Brazilian Health Surveillance Agency (2003) Resolution - RDC n. 359, of December 23, 2003 (Approves the Technical Rules for Packaged Food Serving Sizes for Purposes of Food Labelling). Brasília, DF: ANVISA.

26. Kliemann N, Veiros MB, González-Chica DA et al. (2014) Reference serving sizes for the Brazilian population: an analysis of processed food labels. Rev Nutr 27, 329-341. 
27. Kaufman LR \& Rousseeuw PJ (1990) Finding Groups in Data: An Introduction to Cluster Analysis. Hoboken, NJ: John Wiley \& Sons, Inc.

28. Instituto Brasileiro de Geografia e Estatística (2010) Pesquisa de orçamentos familiares 2008/2009. Avaliação Nutricional da Disponibilidade Domiciliar de Alimentos no Brasil. Rio de Janeiro, RJ: IBGE.

29. Pan American Health Organization/World Health Organization (2016) Pan American Health Organization Nutrient Profile Model. Washington, DC: PAHO.

30. Public Health England (2016) EatWell Guide. London: PHE; available at https://www.gov.uk/government/publications/ the-eatwell-guide

31. Ministry of Health (2014) Dietary Guidelines for the Brazilian Population, 2nd ed. Brasilia, DF: Ministry of Health.

32. World Health Organization (2004) Global Strategy on Diet, Physical Activity and Health. Geneva: WHO.

33. Cowburn G \& Stockley L (2005) Consumer understanding and use of nutrition labelling: a systematic review. Public Health Nutr 8, 21-28.

34. Temple NJ \& Fraser J (2014) Food labels: a critical assessment. Nutrition 30, 257-260.

35. Canadian Food Inspection Agency (2016) Mandatory Labelling of Sweeteners. http://www.inspection.gc.ca/food/labelling/ food-labelling-for-industry/sweeteners/eng/1387749708758/ 1387750396304? chap=2 (accessed May 2017).

36. Silveira BM, Kliemann N, Silva DP et al. (2013) Availability and price of food products with and without trans fatty acids in food stores around elementary schools in low- and medium-income neighborhoods. Ecol Food Nutr 52, 63-75.

37. Kliemann N, Veiros MB, González-Chica DA et al. (2016) Serving size on nutrition labeling for processed foods sold in Brazil: relationship to energy value. Rev Nutr 29, 741-750.

38. Kliemann N, Veiros MB, González-Chica DA et al. (2014) Is the serving size and household measure information on labels clear and standardized? Analysis of the labels of processed foods sold in Brazil. Vigil Sanit Debate 2, 62-68.

39. Kraemer MV, Oliveira RC, Gonzalez-Chica DA et al. (2016) Sodium content on processed foods for snacks. Public Health Nutr 19, 967-975.

40. Kraemer MVS, Machado PP, Kliemann $\mathrm{N}$ et al. (2015) The Brazilian population consumes larger serving sizes than those informed on labels. Br Food J 117, 719-730.

41. Machado PP, Kraemer MVS, Kliemann N et al. (2016) Serving sizes and energy values on the nutrition labels of regular and diet/light processed and ultra-processed dairy products sold in Brazil. $B r$ Food $J$ 118, 1579-1593.

42. Nishida W, Fernandes AC, Veiros MB et al. (2016) A comparison of sodium contents on nutrition information labels of foods with and without nutrition claims marketed in Brazil. Br Food J 118, 1594-1609. 